\title{
British cancer death rates fell by 12\% between 1972 and 2002
}

\author{
Zosia Kmietowicz London
}

\begin{abstract}
More people than ever in Britain are surviving cancer thanks largely to changes in lifestyle, screening services, earlier diagnoses, and prompt treatments, the latest figures have shown. Death rates have been falling while the incidence has been increasing.
\end{abstract}

Figures from Cancer Research UK show that the death rate for people dying from cancer in the United Kingdom fell by 12\% between 1972 and 2002, although the rate of decrease in men is three times the rate in women $(18 \% v 6 \%)$

Improvements in mortality have been seen in the common cancers, such as breast, lung, and bowel cancer, as well as in the less common cancers, such as cancer of the stomach, bladder, and testis and in lymphomas and leukaemia.

The biggest fall in deaths was for stomach cancer. Since 1972 there has been a fall of $65 \%$ in the death rate both in men and in women from this type of cancer, which largely reflects falls in incidence. Deaths from bowel cancer also fell significantly, with a drop in death rates of $27 \%$ in men and $43 \%$ in women, mainly because of better detection and treatment of the disease.

In the same period, mortality from breast cancer in women has fallen by $20 \%$ and mortality from testicular cancer has fallen by $37 \%$.

However, the figures for lung cancer again show an unequal split between the sexes. Whereas the death rate in men has fallen by $47 \%$ over the period studied, among women, the death rate from lung cancer has risen by $55 \%$, reflecting the fact that since the 1950 s many men have given up smoking while more women have taken up the habit.

Professor Peter Selby, director of the Cancer Research UK Unit at St James's Hospital, Leeds, said that with more research into new treatments and screening programmes survival from cancer could increase from the $40 \%$ figure as it stands now to $50 \%$. The scientific knowledge base for cancer is so "breathtaking" that it provides

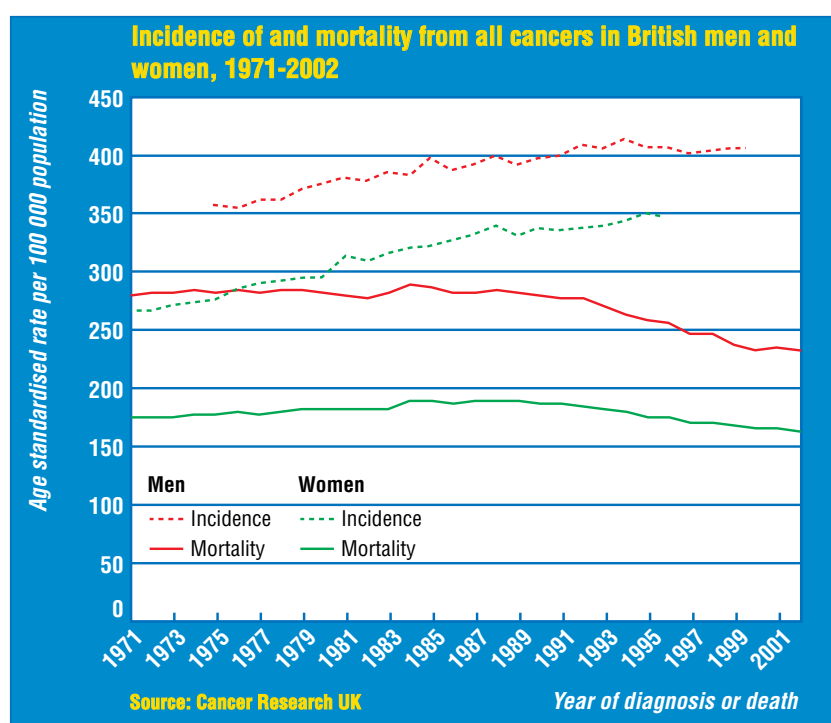

"an amazing opportunity to develop treatments for the future," he said.

Professor Michel Coleman, professor of epidemiology and vital statistics, London School of Hygiene and Tropical Medicine, said: "The rate from cancer deaths may be falling, but the number of people being diagnosed with cancer is increasing, which indicates that we need more strategies to research needs to continue and accelerate so that more people survive the disease in the next generation." prevent cancer. The funding of

\section{FDA advisory panel calls for suicide warnings over new antidepressants}

Ray Moynihan Washington

In a surprise move on 2 February, a panel of scientific advisers of the US Food and Drug Administration urged the agency to warn that new anti-depressants may increase the risk of suicidal thinking or behaviour among children and teenagers.

During a 10 hour hearing, experts weighed the official presentations of uncertain scientific data against powerful emotional testimony from dozens of families whose children have killed themselves or others after taking a selective serotonin reuptake inhibitor-a class including fluoxetine (Prozac), sertraline (Zoloft), and paroxetine (Paxil, Seroxat).

Sara Bostock told how her daughter Cecily stabbed herself to death with a large kitchen knife after taking paroxetine for two weeks. Cecily had recently graduated from Stanford, just received a large pay increase, and was close to a boyfriend and other loved ones.

Asking the Food and Drug Administration to continue studying the issue, the panel also decided to recommend "stronger warnings" about the suicide risks. The move lags behind earlier and stricter recommendations against paediatric use in the United Kingdom for most of these drugs, but it was nevertheless unexpected in the United States, where drug advertising is pervasive and prescriptions have risen sharply in recent years.

In 2002 almost 11 million prescriptions of selective serotonin reuptake inhibitors were written for people under 18 , including more than five million for sertraline and paroxetineneither of which are approved for children in the United States.

Mark Hudak, a panel member and a University of Florida professor, speaking towards the close of Monday's meeting, said:
"If they are clearly very ill, anything that can be done should be done. [For a] lot of the people who spoke this morning, the picture they presented of their child was not someone who was very, very ill. It was someone with [milder illness] who was put on these drugs with terrible consequences. Something needs to be done to educate practitioners."

FDA officials expressed great frustration that drug companies had been slow in supplying data from their unpublished antidepressant trials. GlaxoSmithKline was singled out for mislabelling suicide related events that were possibly associated with paroxetine under the heading "emotional lability." 